\title{
Mental health law in Ghana
}

\author{
George Hudson Walker ${ }^{1}$ and Akwasi Osei
}

${ }^{1}$ University of Leeds, UK, email um10gw@leeds.ac.uk ${ }^{2}$ Accra Psychiatric Hospital, Ghana, email akwasiosei2014@ gmail.com

\begin{abstract}
In 2012 Ghana passed a new Mental Health Act, which aimed to create a new system of mental healthcare in Ghana. The Act includes provisions for the creation of a modern, community-based mental health system and for the protection of the rights of persons with mental disorders. This article discusses the implications of the Act and the progress which has been made towards its implementation.
\end{abstract}

Ghana has a population of over 25 million. It became a lower middle-income country in 2011 after a period of rapid growth. Ghanaians born today are predicted to have a life expectancy of 61 years. It is estimated that around $21 \%$ of adult Ghanaians experience moderate or severe psychological distress at any time (Canavan et al, 2013). In 2011 there were 4.88 trained mental health staff per 100000 population, below the 6.0 per 100000 average of other lower middle-income countries. Most of the resources for mental health are clustered around the three public psychiatric hospitals situated in the south of the country (Roberts et al, 2013). There is limited provision for specialist psychiatry services for forensic patients, children with intellectual disabilities, elderly patients and those requiring rehabilitation (Kleintjes et al, 2010). The budget available for mental healthcare in 2011 was $1.4 \%$ of the total health budget (Roberts et al, 2013).

\section{History of mental health legislation}

As a former colony of the UK, the legal and governance systems of Ghana are modelled upon the British systems as they existed at the time of colonial rule. In 1957 independence was declared and the area known as the Gold Coast became Ghana. Ghana today exists as a multi-party democracy; after a period of military rule, the current constitution was approved in 1992.

The first piece of mental health legislation was the 1888 Lunatic Asylum Act of the Gold Coast. In 1972 that Act was replaced by a Mental Health Decree (NRCD 30), which was, however, never implemented (Doku et al, 2012).

\section{Mental Health Act 2012 (Act 846)}

In 2012 a new Mental Health Act was enacted by Parliament after 8 years of widely consultative development and political process, replacing the unimplemented Mental Health Decree of 1972 (Osei et al, 2011). The Act has been endorsed by the World Health Organization (WHO) as an example of best practice in mental health legislation. It now has the potential to improve the provision of mental healthcare in Ghana and to provide a model for other low- and middle-income countries. Its key provisions are set out in Box 1. The overall aims are: to ensure the rights and quality treatment of persons with mental disorder; and to stipulate changes to the organisation, provision and funding of mental health services.

The provision of mental healthcare was previously overseen by the Mental Health Unit of the Institutional Care Division of the Ghana Health Service (GHS). While the GHS will still be responsible for implementing mental healthcare in the regions and communities, the new Mental Health Authority will now have oversight of the implementation of, and ensure compliance with, quality mental healthcare. The Act states that funding for the Authority will come from the Mental Health Fund established by the Act. The levy for the Fund has not yet been specified and will be confirmed with the passage of the Legislative Instrument that will set out the details of the provisions of the Act.

Organisational changes described in the Act focus on creating a new system of decentralised mental healthcare provided within communities throughout the country; regional and district mental health subcommittees will have a duty to ensure that multidisciplinary mental healthcare is available within existing medical services in every district.

The Act aims to ensure the rights of persons with mental disorder, as indeed they are entitled by the constitution. Rights will be ensured: through provisions against discrimination in everyday life and employment; by the setting out of clear procedures and safeguards for voluntary and involuntary admissions; and by protecting specific vulnerable groups such as the elderly, people with intellectual disabilities and women. It is hoped that these provisions will go some way towards addressing stigma and reducing its negative consequences, such as eviction, unemployment

Box 1. Key aspects and provisions of Ghana's Mental Health Act 846 of 2012

- Rights of persons with mental disorder

- Protection of vulnerable groups

- Procedures for voluntary and involuntary admission and treatment

- Creation of the Mental Health Authority

- Establishment of mental health review tribunals

- Establishment of regional visiting committees

- Establishment of the Mental Health Fund

- Introduction of sanctions for the offences of neglect of or discrimination against persons with mental disorder 
and abandonment. The Act makes provision for the removal, assessment, treatment and rehabilitation of homeless persons with mental disorder.

Only accredited institutions are now able to admit patients against their will, meaning that unorthodox facilities such as prayer camps will no longer be able to keep patients chained or secluded. To ensure their compliance and to investigate complaints, institutions will be subject to inspection by visiting committees, which will have the power to visit all mental health facilities.

\section{Implementation of the Act}

After the 8-year process of bringing the bill from inception to enactment, it was accepted that there would be significant challenges in implementing the Act.

At the time of enactment, Doku et al anticipated challenges in the domains of: service organisation; human resources and the need for development of expertise in mental healthcare, allied health professions and the judiciary; increased demands placed upon social services and the legal system; the need for strengthening of mental health information systems; and the financial implications of the Act (Doku et al, 2012).

In 2014 a study was conducted to determine the barriers to the implementation of the Act, as seen by key stakeholders. The 12 stakeholders interviewed included psychiatrists and mental health nurses working in the GHS, members of the board of the Mental Health Authority and key figures from non-governmental organisations working in the field (Walker, 2015). The concerns of Doku et al regarding financial challenges, human resource shortfalls and the inadequacies of the legal infrastructure were confirmed by the participants. Of the barriers described by the stakeholders (Box 2 ), the most immediate was that of the delay in parliamentary process, that is, the passing of the Legislative Instrument, so that resources for implementation could be made available.

Moving forward, stakeholders felt that efforts should be focused on: advancing the legislative instrument, securing funding for the Authority, widespread public education, and the development of human resources and infrastructure - such as the medicines supply chain and legal infrastructure required for the functioning of the mental health review tribunals. The immediate correction of human rights breaches was seen as a priority, along with the training of the judiciary in the application of the new law (Walker, 2015).

Box 2. Identified barriers to the implementation of the 2012 Act

- Limited dissemination so far

- Delays in the parliamentary process for the passing of the Legislative Instrument

- Poor access to patients in non-orthodox mental health facilities

- Inadequate financial resources for implementation

- Inadequate human resources

- Inadequate infrastructure for mental healthcare provision

\section{The future}

The Legislative Instrument has been reviewed by the Attorney General's office and has been submitted to Parliament for approval. In the short term, it is now time to develop strategic plans for the implementation of the Act once the Legislative Instrument is in place; a 4-year strategic plan has been developed and a 10 -year policy is being drafted. The chaining of patients can now be addressed and any violation of rights will be sanctioned legally; education programmes will be developed for the public, media, judiciary, traditional and faith healers in order to reduce stigma and ensure compliance with the Act.

In the medium term, the Mental Health Act must be harmonised with international legislation to which Ghana is a signatory, such as the United Nations Convention for the Rights of Persons with Disabilities (UNCRPD), as well as Ghanaian legislation relevant to mental health. The Persons with Disability Act of Ghana and the Criminal Code of Ghana - which criminalises suicide, for example will both need updating.

Changes to the provision of mental health services will begin as the Authority becomes established - one of the ten regional subcommittees has been formed and the rest will follow, along with district committees, mental health review tribunals and visiting committees. This will allow for the gradual decentralisation and integration of mental healthcare into the general healthcare system; the three existing large psychiatric hospitals will be down-sized as small psychiatric wings are built into regional and district hospital facilities. People on the street who are mentally ill can then be referred for assessment and treatment as services become available.

The Authority will then look to establish drug rehabilitation centres and halfway homes, as well as establishing its own drug procurement systems. As the Authority develops it will move towards data collection and the production of research on services provided - which will be essential for guiding future strategy and service improvement.

With the passing and implementation of the Mental Health Act, the future looks promising.

\section{References}

Canavan, M. E., Sipsma, H. L., Adhvaryu, A., et al (2013)

Psychological distress in Ghana: associations with employment and lost productivity. International Journal of Mental Health Systems, 7,9.

Doku, V., Wusu-Takyi, A. \& Awakame, J. (2012) Implementing the Mental Health Act in Ghana: any challenges ahead? Ghana Medical Journal, 46, 241.

Kleintjes, S., Lund, C., Flisher, A., et al (2010) A situational analysis of child and adolescent mental health services in Ghana, Uganda, South Africa and Zambia. African Journal of Psychiatry, 13, 132-139.

Osei, A., Roberts, M. \& Crabbe, J. (2011) The new Ghana Mental Health Bill. International Psychiatry, 8(1), 8-9.

Roberts, M., Asare, J., Mogan, C., et al (2013) The Mental Health System in Ghana - WHO AIMS Report. Kintampo Project/Ghana Ministry of Health.

Walker, G. (2015) Ghana Mental Health Act 846 2012: a qualitative study of the challenges and priorities for implementation. Ghana Medical Journal, 49, 266-274. 